\title{
Effect of Surface Porosity on Tribological Properties of Sintered Pure Al and Al 6061
}

\author{
Avijit Sinha*, Zoheir Farhat \\ Department of Process Engineering and Applied Science, Materials Engineering Program, Dalhousie University, \\ Halifax, Canada \\ Email: ${ }^{*}$ avijit.sinha@dal.ca
}

Received 20 April 2015; accepted 19 June 2015; accepted 24 June 2015

Copyright (C) 2015 by authors and Scientific Research Publishing Inc.

This work is licensed under the Creative Commons Attribution International License (CC BY).

http://creativecommons.org/licenses/by/4.0/

(c) (i) Open Access

\begin{abstract}
Due to light weight, high specific strength, high corrosion resistance and good heat transfer ability, aluminium alloys are becoming attractive for critical structural applications. These alloys can be manufactured using powder metallurgy techniques in which porosity is a common characteristic. The presence of pores is responsible for decreasing effective load bearing cross sectional area and inducing stress concentration sites for strain localization and damage, decreasing both strength and ductility. The present study aims to establish a better understanding of the relationship between surface porosity and corresponding wear behavior. In this study, porous specimens were produced using powder metallurgy technique and the extent of wear damage and the type of wear was investigated under low load range of 1.5 - $5 \mathrm{~N}$ against AISI 52100 bearing steel ball using a reciprocating ball-on-flat configuration and frequency of $10 \mathrm{~Hz}$. Scanning electron microscopy of the wear tracks and wear debris was carried out to understand wear mechanisms. This study revealed that due to combined effect of high stress intensity and subsurface cracking, wear rate increases with increasing porosity content. The friction and wear behavior of pure $\mathrm{Al}$ and $\mathrm{Al} 6061$ as a function of porosity content can be attributed to their hardness and corresponding wear mechanism.
\end{abstract}

\section{Keywords}

Aluminium, Powder Metallurgy, Microstructure, Porosity, Wear

\section{Introduction}

Wear is one of the main causes for component damage and subsequent failure of machines and devices. Its mitigation by appropriate material choice, coating, surface design or lubrication is therefore of high economic

\footnotetext{
"Corresponding author.
} 
importance. Wear is related to interactions between surfaces and more specifically the removal and deformation of material on a surface as a result of mechanical action of the opposite surface. Wear is affected by many material and environmental variables and leads to loss of material and dimension [1]. The wear of materials may occur due to adhesion, abrasion, surface fatigue or tribo-chemical reaction.

Aluminium alloys have been recently used in tribo components involving sliding movement with a contacting counter body [2]. The wear response of these components greatly depends on their material-related parameters, the nature, shape, size, content, and mode of distribution of given micro constituents (porosity and second phase particles) [3]. In addition, many studies showed that there are other factors such as load, test duration, temperature, humidity affect wear mechanisms and wear resistance. It has been observed that even a minor alteration in any of the material parameters and operating conditions can change the sliding wear behavior significantly [4] [5].

Porosity is a common defect in sintered aluminium alloys and strongly influences their properties and applications. The presence of porosity is accompanied by a decrease in mechanical properties such as strength and ductility of the material [6]. The influence of porosity on wear behavior of materials has been controversial in several studies and is not clearly understood [7] [8]. It has been reported in some studies as beneficial and in others as detrimental. Chen et al. [9] investigated the influence of porosity on composite materials and they concluded that porosity could be beneficial to the performance of materials under some conditions. They suggested that, porosity may help absorb impact energy that accompanies crack splitting, which, reduces crack propagation, thus delays rapid fracture. A study conducted by Simchi and Danninger [10] indicated a positive influence of porosity on wear behavior. They showed that porosity acts as lubricant reservoirs in wet sliding conditions, which provides a considerable advantage in wear process.

Generally, the presence of pores has a detrimental effect on the wear performance of materials [11]-[23]. Pores act as pre-existing incipient cracks in the subsurface layer, waiting to become unstable at an appropriate stress level [24]. Porosity is accompanied by a decrease in mechanical properties of materials such as strength and ductility [25]-[27]. For instance, Deshpande and Lin [28] reported that porosity in materials decreased their wear resistance due to the no-load bearing characteristics of pores on the wear surface. They also suggested that depending on pore geometry and distribution, wear resistance varies and may promote severe wear. Hardin and Beckermann [29] demonstrated an apparent reduction in elastic moduli of components due to the presence of pores. Experiments performed by Suh [30] have found that an increase in porosity content reduces the required length of cracks needed to link up pores which later promotes delamination. The influence of porosity on the wear and friction of metals has been investigated by Vardavoulias et al. [31] and they reported that the pores enhance surface roughness of the materials, decrease the real area of contact between two sliding surfaces and consequently increase the contact pressure and promote particle detachment during sliding. Gui et al. [32] considered the pores as crack sources which can be created when an external force is applied. In general high porosity in materials leads to low strength and high wear rate [33].

Actual effect of porosity on the wear behavior of materials depends on several parameters such as size and shape of pores and amount and distribution of porosity. To employ these materials in real applications it is important to establish a fundamental understanding of their microstructural characteristics on wear properties.In the present work, an attempt is made to identify the relationship between surface porosity and wear behavior. Pure $\mathrm{Al}$ and $\mathrm{Al} 6061$ specimens were prepared having a range of porosity by employing $\mathrm{P} / \mathrm{M}$ technique and a series of reciprocating wear tests were conducted under different loads and wear mechanisms were investigated.

\section{Experimental Methods}

\subsection{Raw Powders Characterization}

Pure $\mathrm{Al}$ and $\mathrm{Al} 6061$ raw powders were prepared for SEM analysis to examine particle morphology and approximate particle size. The appearance of these powders is shown in Figure 1. Both powders exhibit a somewhat spherical shape. The measured chemistries of each powder and particle size distribution data are summarized in Table 1 and Table 2. The composition of these powders was determined using atomic absorption unit. Particle size analysis on the raw powders was performed using a Malvern particle size analyzer (model 2600c) equipped with MASTER particle sizer 3.1 analytical software. Here tests were conducted using a focal length of $100 \mathrm{~mm}$ and a beam length of $300 \mathrm{~mm}$. 

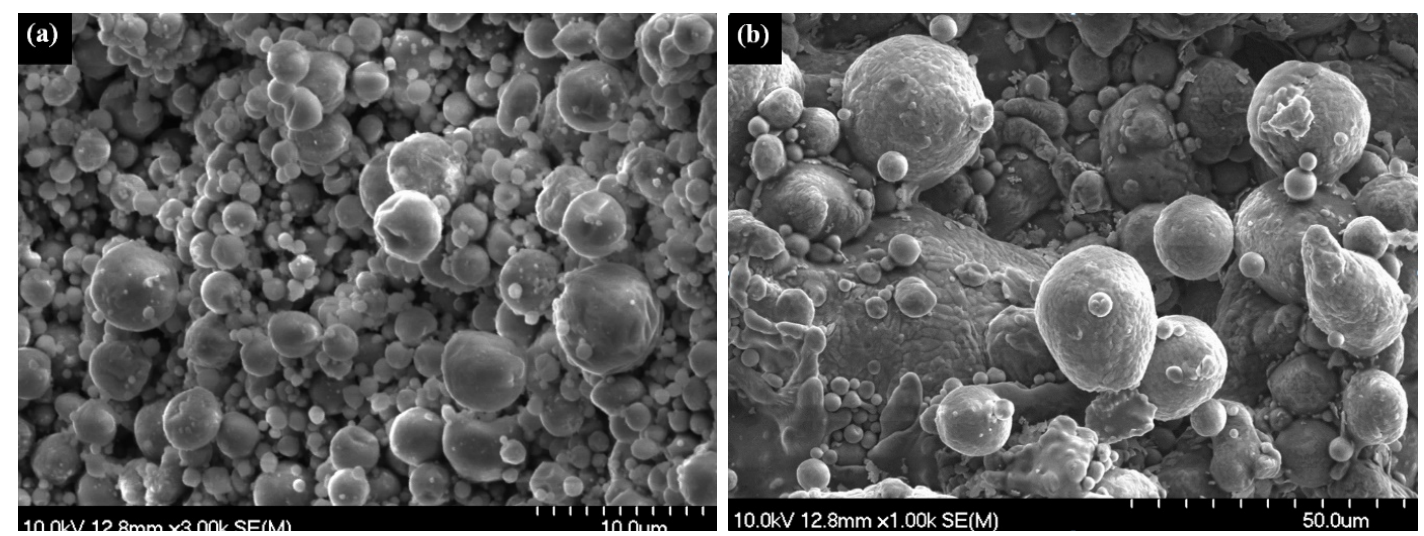

Figure 1. SEM images of raw powders. (a) Pure Al; (b) Al 6061.

Table 1. Chemical composition of pure $\mathrm{Al}$ and $\mathrm{Al} 6061$ powders.

\begin{tabular}{ccccccc}
\hline Elements (\%) & Al & Mg & Si & Fe & Cu & Zn \\
\hline Pure Al & 99.9 & 0.03 & 0.03 & 0.01 & 0.01 & 0.02 \\
Al 6061 & 97.5 & 1 & 0.6 & 0.5 & 0.2 & 0.2 \\
\hline
\end{tabular}

Table 2. Particle size data for pure $\mathrm{Al}$ and $\mathrm{Al} 6061$.

\begin{tabular}{cc}
\hline Specimen & Average particle size $(\boldsymbol{\mu m})$ \\
\hline Pure Al & 3.56 \\
Al 6061 & 70.9 \\
\hline
\end{tabular}

\subsection{Materials Preparation}

The powders were weighed using a Denver Instruments APX-1502 scale and placed in Nalgene bottle. A total of $0 \%, 1.5 \%, 10.5 \%$ and $14.5 \%$ lubricant (Lico wax C) were added to the powders separately and then blended in a Turbula Model T2M mixer for 40 minutes to ensure homogeneity. Rubber molds were filled with the blended powders and sealed with electrical tape. The sealed molds were then transferred to cold isostatic press (CIP) chamber for wet bag pressing. The chamber was then filled with a mixture of water and water soluble oil (20:1). Using a high pressure air-operated piston type pump, the pressure within the pressure chamber was increased to $200 \mathrm{MPa}$ and maintained for a dwell time of 5 minutes. Using the decompression valve, the pressure was then reduced at a rate of $1 \mathrm{ksi} / \mathrm{s}$ to atmospheric pressure and molds removed. The net result was that the loose powder was pressed into a single coherent body of the same shape (but not dimensions) as the rubber mold. This material, a "green body", was very porous, brittle and friable. To increase density, green bodies were subsequently sintered. The sintering of compacted samples was conducted in a Linderburg Blue 3-Zone Tube Furnace Model STF55666C- 1 at $560^{\circ} \mathrm{C}$ for 20 minutes and then slow cooled to $480^{\circ} \mathrm{C}$.

The green and sintered densities of samples were determined in accordance with MPIF standard 42. The unsintered (green) density of the samples was calculated for each sample by weighing the samples in air $\left(W_{\text {air }}\right)$ and after immersion in water $\left(W_{\text {water }}\right)$. The temperature of water was recorded. The green density was calculated using $\rho_{\text {Green }}=w_{\text {air }} \rho_{\text {water }} /\left(W_{\text {air }}-W_{\text {water }}\right)$, where $\rho_{\text {water }}$ is the density of water measured using $\rho_{\text {water }}=7 \times 10^{-8} T^{3}$ $-1 \times 10^{-4} T+0.9996$, where $T$ is the measured temperature of the water in degree celsius. The sintered density was measured by weighing the samples in air ( $W_{\text {air }}$ ), prior to infiltrating them with ESSO-NUTO H46 hydraulic oil, then weighing the samples in air (with oil impregnation). Finally, oil impregnated samples were weighed in water and the sintered density was calculated as follows: $\rho_{\text {sintered }}=W_{\text {air }} \rho_{\text {water }} /\left(w_{\text {ao }}-w_{\text {wo }}\right)$, where $w_{\text {ao }}$ is the weight of the oil infiltrated specimen in air and $w_{\text {wo }}$ is the weight of the oil infiltrated specimen in water. The green and sintered density values of the samples are given in Table 3 and Table 4 . The volume percentage of porosity is calculated using $100-\left(\frac{\text { sintered density }}{\text { theoritical density }} \times 100\right)$, where the theoretical densities of pure $\mathrm{Al}$ and $\mathrm{Al}$ 6061 are $2.69 \mathrm{~g} / \mathrm{cc}$ and $2.70 \mathrm{~g} / \mathrm{cc}$ respectively. 
Table 3. Basic properties of sintered pure Al.

\begin{tabular}{cccc}
\hline Pure Al & Green density (g/cc) & Sintered density $\mathbf{( g / c c )}$ & Volume porosity (\%) \\
\hline No wax & 2.51 & 2.62 & 2.7 \\
$\mathbf{1 . 5 \%}$ wax & 2.32 & 2.40 & 11 \\
$\mathbf{1 0 . 5 \%}$ wax & 1.98 & 2.05 & 24 \\
$\mathbf{1 4 . 5 \%}$ wax & 1.56 & 1.78 & 34 \\
\hline
\end{tabular}

Table 4. Basic properties of sintered Al 6061.

\begin{tabular}{cccc}
\hline Al 6061 & Green density (g/cc) & Sintered density (g/cc) & Volume porosity (\%) \\
\hline No wax & 2.49 & 2.52 & 6.6 \\
$\mathbf{1 . 5 \%}$ wax & 2.24 & 2.32 & 14 \\
$\mathbf{1 0 . 5 \%}$ wax & 1.75 & 1.86 & 31 \\
$\mathbf{1 4 . 5 \%}$ wax & 1.48 & 1.57 & 41 \\
\hline
\end{tabular}

Specimens were cut from the powder compacts and were prepared for metallographic examination by using 240, 320, 400 and $600 \mathrm{SiC}$ abrasive papers for grinding and 0.1, 0.3 and 0.05 alumina suspensions for polishing. Olympus BX51 research microscope, equipped with bright field objectives was used to analyze the microstructure at high resolution. Surface porosities of samples were calculated using image analysis software. A series of images were taken to cover the whole surface area of the sample. Porosity was identified based on their graylevel intensity differences compared to the matrix.

\subsection{Scratch Testing}

Scratch tests were performed using a Universal Micro-Tribometer (UMT). This test method utilizes a diamond indenter that slides against a linear sliding motion, having a scratch length of $5 \mathrm{~mm}$. All tests were conducted at room temperature and at a relative humidity of $40 \%-50 \%$. The load is applied downward against the flat specimen. The tester allows for monitoring the dynamic load, friction force. A Rockwell diamond indenter tip of radius 200 micron was used in the test. The instantaneous values of calibrated normal load $\left(F_{z}\right)$, tangential load $\left(F_{x}\right)$ were measured and recorded using a data acquisition system. Pure $\mathrm{Al}$ and $\mathrm{Al} 6061$ specimens were tested under the same time interval $30 \mathrm{~s}$. Single pass scratch tests were performed using a constant $1 \mathrm{~N}$ load and a velocity $0.166 \mathrm{~mm} / \mathrm{s}$.

\subsection{Wear Testing}

Dry sliding reciprocating wear tests were performed using a Universal Micro-Tribometer. This test method utilizes a ball upper specimen that slides against a flat lower specimen in a linear, back and forth sliding motion having a stroke length of $5.03 \mathrm{~mm}$. All tests were conducted at room temperature and at a relative humidity of $40 \%-55 \%$. The load is applied downward through the ball counter-face against a flat specimen mounted on a reciprocating drive. The tester allows for monitoring the dynamic normal load and friction force of the wear track during the test. A 6.3 mm diameter AISI 52100 bearing steel ball with a hardness of HRA 83 was used as a counter-face material. The ball was mounted inside a ball holder, which is attached directly to a suspension system. The suspension system is attached to a load sensor that controls and records forces during the test. The weight of the specimen was measured before and after each wear test to determine individual weight loss at selected time intervals. Six different loads (1.5, 2, 2.5, 3, 4, 5 N) were employed; each tested under $10 \mathrm{~Hz}$ frequency and for 120 minutes.

\subsection{Rockwell Hardness and Nanoindentation}

Rockwell hardness tests were carried out on all specimens of pure Al and Al 6061 alloy. Tests were performed on a Leco R600 Rockwell hardness tester using the " $\mathrm{H}$ " scale under a load of $60 \mathrm{~kg}$ and a diamond indenter. Nanoindentation experiments were conducted using a nanoindentation system having a nanohardness head and a controller attached to a CETR multifunctional tribometer system. The instrument uses a Berkovich diamond 
pyramid with an angle of $65.3^{\circ}$ between the tip axis and the faces of the triangular pyramid. The total penetration depth consists of a plastic component and an elastic recovery component which occurs during the unloading. Maximum indentation depth $\left(h_{\max }\right)$ can be expressed as:

$$
h_{\max }=h_{\mathrm{c}}+\left[\frac{(\pi-2)}{\pi}\right]\left(\frac{2 P_{\max }}{\mathrm{d} p / \mathrm{d} x}\right)
$$

where $p$ and $h$ are load and indentation depth, respectively. $h_{\max }, P_{\max }$, and slope at maximum load $\mathrm{d} p / \mathrm{d} x$ are determined from the load versus displacement profile.The relationship between $H$ and the maximum applied load $\left(P_{\max }\right)$ is as follows:

$$
H=\frac{P_{\max }}{A}
$$

where $A$ is the area of contact and for Berkovich indenter and is given by,

$$
A=24.5 h_{c}^{2}
$$

where $h_{c}$ is the contact depth. The elastic modulus can be expressed as

$$
E^{*}=\frac{1}{2} \frac{\mathrm{d} p}{\mathrm{~d} h} \frac{\sqrt{\pi}}{\sqrt{A}}
$$

where

$$
\frac{1}{E^{*}}=\frac{1-v_{1}^{2}}{E_{1}}+\frac{1-v_{2}^{2}}{E_{2}}
$$

Here, $E_{2}$ and $V_{2}$ are elastic modulus and Poisson's ratio of the test material and $E_{1}$ and $V_{1}$ are the same parameters for Berkovich indenter. Twelve indentations were performed on each specimen on random location and data was averaged.

\section{Results and Discussion}

\subsection{Microstructure and Surface Morphology}

The size, shape and amount of pores are largely dependent on processing parameters, such as, the amount of lubricant and compaction pressure. During sintering, the lubricant is burned off leaving behind a porous structure. The higher the amount of lubricant, the higher the porosity. Moreover, lower compaction pressure leads to higher porosity and reduced density of compacts.

Different surface characteristics were observed by varying the amount of lubricant used. Pure $\mathrm{Al}$ specimen with no wax has shown the least amount of surface porosity. Surface porosity ranges from $1.9 \%$ for no wax to $15.1 \%$ for $14.5 \%$ wax. On the other hand, volume percent porosity ranges from $2.7 \%$ to $34 \%$ respectively. From Figures 2(a)-(d) it is clearly observed that with increasing the percentage of lubricant, the amount of porosity, size and shape of pores change significantly. The dark spots in Figure 2 indicate porosity. Pores became more uniformly distributed and larger in size when using higher amounts of lubricant which is clearly visible from Figures 2 (c)-(d).

In the case of $\mathrm{Al} \mathrm{6061,} \mathrm{porosity} \mathrm{content} \mathrm{was} \mathrm{higher} \mathrm{than} \mathrm{pure} \mathrm{Al}$ for the same amount of lubricant. The surface porosity ranges from $3.5 \%$ for no wax to $20.7 \%$ for $14.5 \%$ wax (Table 5). On the other hand, volume percent porosity ranges from $6.6 \%$ to $41 \%$ respectively. Figures $3(a)$-(d) show significant increase in pore size when the amount of lubricant is increased.

As all the specimens were compacted under same pressure and sintered under the same sintering conditions, the amount of lubricant plays the most significant role in determining pore size, shape and amount. The added lubricant flows between $\mathrm{Al}$ powders and impede pore closure during compaction. Pores that are present in the compact are filled by the lubricant. At the time of sintering, lubricant is burned off and pores become visible in those regions of the powder compact. When more lubricant is added, more spaces are occupied by the lubricant during compaction and subsequently larger pores are formed after sintering and as a result the overall porosity content is increased. 

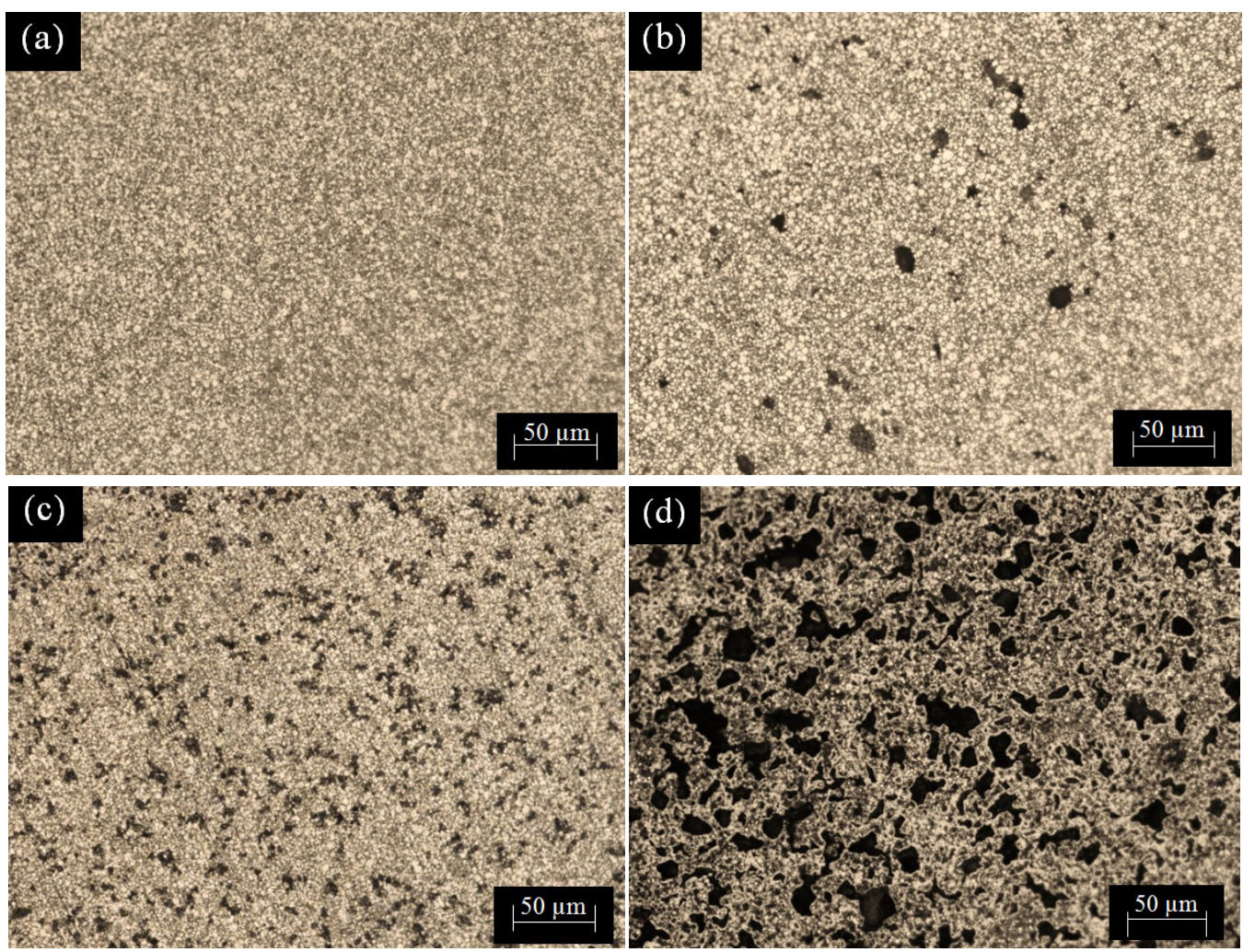

Figure 2. Optical micrographs of pure Al samples mixed with (a) no wax; (b) 1.5\% wax; (c) 10.5 wax; (d) $14.5 \%$ wax.
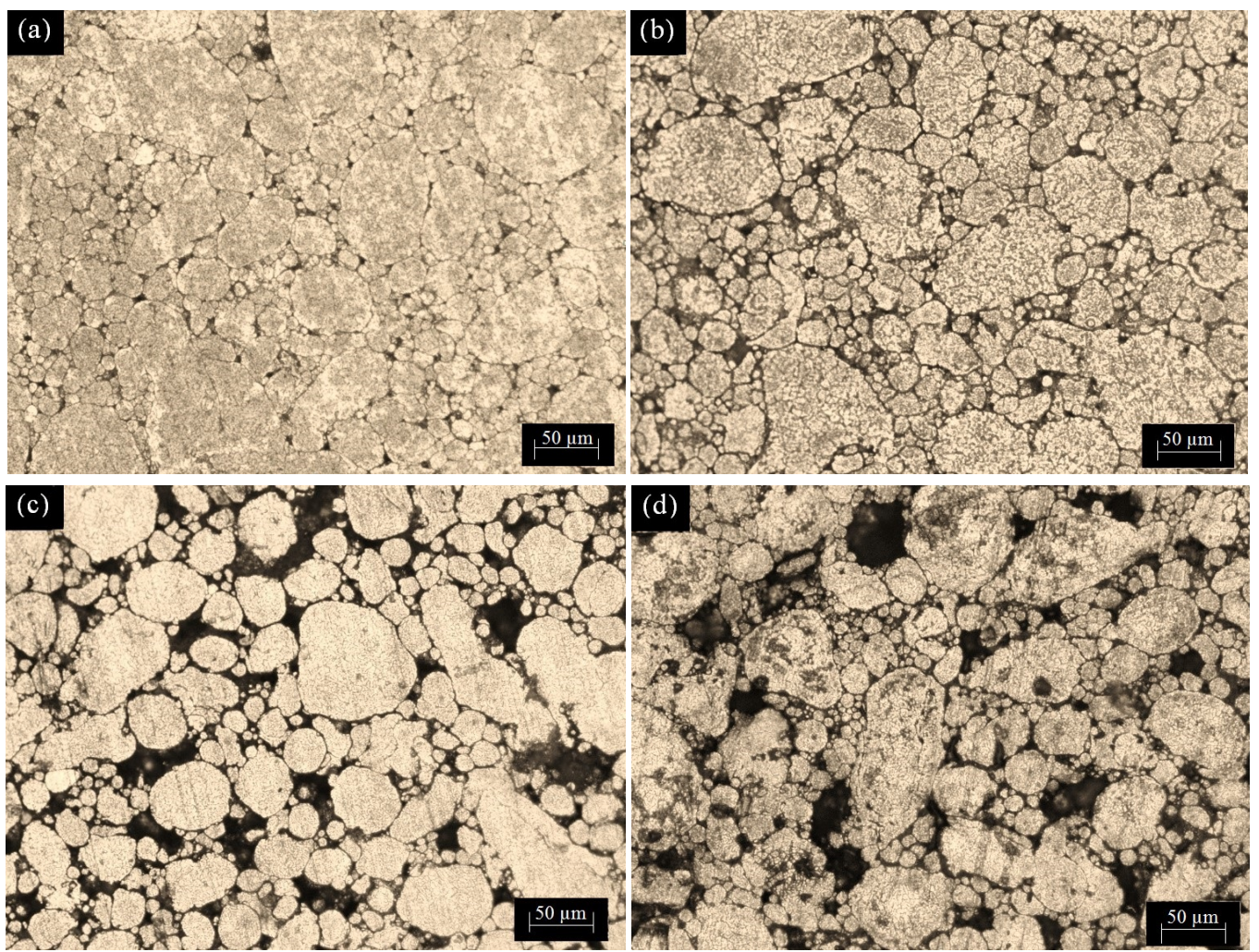

Figure 3. Optical microscopy of Al 6061 samples mixed with (a) no wax; (b) 1.5\% wax; (c) 10.5\% wax; (d) 14.5 wax. 
Table 5. Microstructural characteristics and hardness values of sintered pure $\mathrm{Al}$ and $\mathrm{Al} 6061$.

\begin{tabular}{cccccccc}
\hline Specimen & $\begin{array}{c}\text { Wax } \\
(\mathbf{\%})\end{array}$ & $\begin{array}{c}\text { Al grain size } \\
(\boldsymbol{\mu m})\end{array}$ & $\begin{array}{c}\text { Pore size } \\
(\boldsymbol{\mu m})\end{array}$ & Pore shape & $\begin{array}{c}\text { Volume porosity } \\
(\mathbf{\%})\end{array}$ & $\begin{array}{c}\text { Surface porosity } \\
(\%)\end{array}$ & $\begin{array}{c}\text { Rockwell hardness } \\
(\mathbf{H R H})\end{array}$ \\
\hline & 0 & 5.5 & 2.7 & round & 2.9 & 1.9 & 80 \\
Pure Al & 1.5 & 5.5 & 14.3 & round & 10.8 & 5.8 & 72 \\
& 10.5 & 5.6 & 19.3 & round and irregular & 23.8 & 12.7 & 61 \\
& 14.5 & 5.5 & 27.0 & irregular & 33.9 & 15.1 & 48 \\
& 0 & 45.6 & 12.0 & round & 6.5 & 3.5 & 84 \\
Al 6061 & 1.5 & 46.1 & 20.0 & round & 13.8 & 10.3 & 67 \\
& 10.5 & 45.3 & 28.0 & round and irregular & 30.9 & 16.0 & 23 \\
& 14.5 & 45.7 & 33.0 & round and irregular & 41.7 & 20.7 & 8 \\
\hline
\end{tabular}

Detailed description of Al grain size, pore size and pore shape are given in Table 5 . With increasing porosity content pore size, pore shape and porosity distribution vary over a wide range. For pure Al, the size of the pore changed from $2.7 \mu \mathrm{m}$ at $1.9 \%$ surface porosity to about $27 \mu \mathrm{m}$ for $15.1 \%$ porosity. On the other hand, for Al 6061, pore size increased from $12 \mu \mathrm{m}$ at $3.5 \%$ porosity to about $33 \mu \mathrm{m}$ for $20.7 \%$ porosity. In both cases, surfaces with low porosity content had circular shape pores, but with increasing porosity content, the pores became irregular. It is noticeable from Table 5 that, Al grain size remained almost constant for all Al specimens. For pure $\mathrm{Al}$, the average grain size of all specimens was around $5.5 \mu \mathrm{m}$ and for $\mathrm{Al} 6061$ was around $45.6 \mu \mathrm{m}$.

Generally fine particle sizes tend to have smaller grains and large particle sizes tend to have larger grains. The presence of grain boundaries act as impediments for creating porosity. Due to boundary diffusion, pores that touch grain boundaries may be eliminated. The fewer the number of grain boundaries, the larger the grains and the higher the probability for pore formation. As Al 6061 specimens had larger grain size than pure Al specimens, higher porosity content was observed in those specimens.

\subsection{Effect of Surface Porosity on Hardness}

To investigate the effect of porosity on hardness of pure Al and Al 6061 specimens, a series of Rockwell hardness measurements were conducted and plotted in Figure 4. In both case, with increase in \% surface porosity of the specimens hardness decreases. The hardness of pure $\mathrm{Al}$ containing $1.9 \%, 5.8 \%, 12.7 \%$ and $15.1 \%$ surface porosity are around 80, 72, 61 and $48 \mathrm{HRH}$. On the other hand, the hardness of Al 6061 containing 3.5\%, 10.3\%, $16.0 \%$ and $20.7 \%$ surface porosity are around 84, 67, 23 and 8 respectively. In case of pure Al, a reduction in hardness of about $40 \%$ is observed as surface porosity increases from $1.9 \%$ to $15.1 \%$ and for $\mathrm{Al} 606190 \%$ hardness reduction is observed as porosity increases from 3.5\% to $20.7 \%$. This trend is in agreement with others' work [34]. When porosity increases, load bearing area decreases. Moreover, increased porosity in the subsurface raises the chances for crack nucleation and link-up of pores. This results in weakening of the materials and decreases strength. As Al 6061 specimens have more porosity content than pure Al, reduction in hardness is higher for Al 6061.

Nanoindentation tests were also conducted on all Al specimens and nanohardness and Young's modulus were calculated using Oliver and Pharr methods [35]. Figure 5 shows typical load-depth curves obtained from nanoindentation tests for porous pure $\mathrm{Al}$ and $\mathrm{Al} \mathrm{6061.} \mathrm{The} \mathrm{load} \mathrm{is} \mathrm{defined} \mathrm{as} \mathrm{the} \mathrm{total} \mathrm{force} \mathrm{on} \mathrm{the} \mathrm{indenter} \mathrm{and} \mathrm{the}$ depth is the displacement measured from the indenter starting position.

Influence of porosity on the Young's modulus and nanohardness of the specimens is given in Table 6 .

From the above table, it is clear that, Young's modulus and nanohardness both decrease with increase in surface porosity. In case of pure $\mathrm{Al}$, a reduction in Young's modulus of about $47 \%$ is observed as surface porosity increases from $1.9 \%$ to $15.1 \%$ and for $\mathrm{Al} 6061,82 \%$ reduction is observed as porosity increases from $3.5 \%$ to $20.7 \%$. In case of nanohardness this reduction is about $34 \%$ for pure $\mathrm{Al}$ and $42 \%$ for $\mathrm{Al} 6061$ with same amount of porosity increase. The morphology of the pores immediately beneath the Al matrix or within the zone of influence has a significant effect on the response of the indenter and measured nanohardness and Young's modulus. Especially the size and shape of the pores within the zone control the indenter response. When the indenter tip touches the solid phase, the solid phase resists the tip, but if there are pores beneath the tip, the resistance is reduced. That is, for a given load, the depth of penetration increases with increasing porosity. In this work, for 


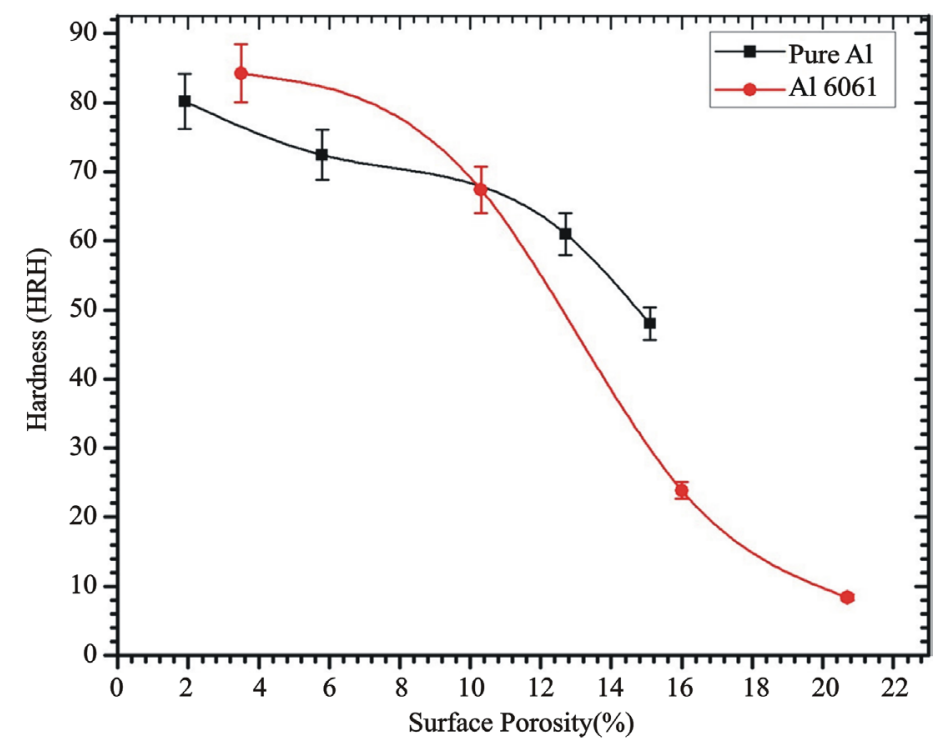

Figure 4. Variation in hardness with surface porosity for pure $\mathrm{Al}$ and $\mathrm{Al} 6061$.

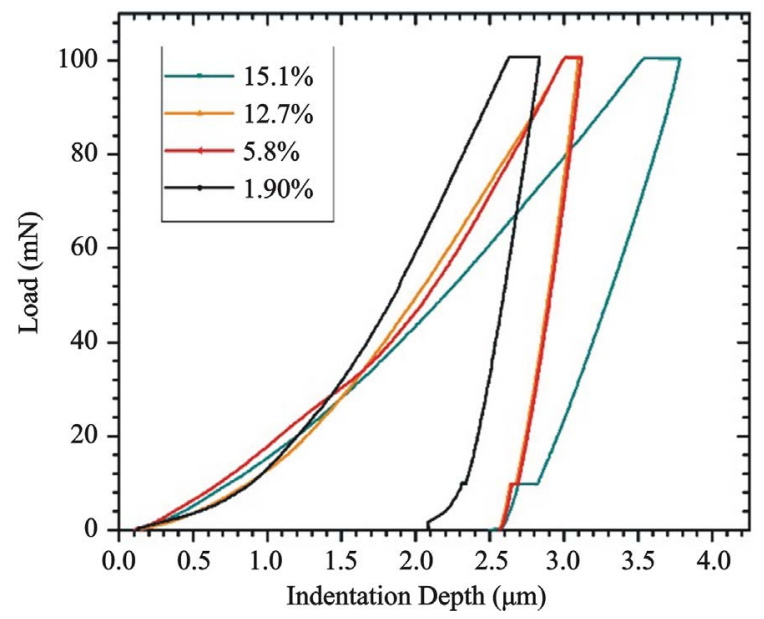

(a)

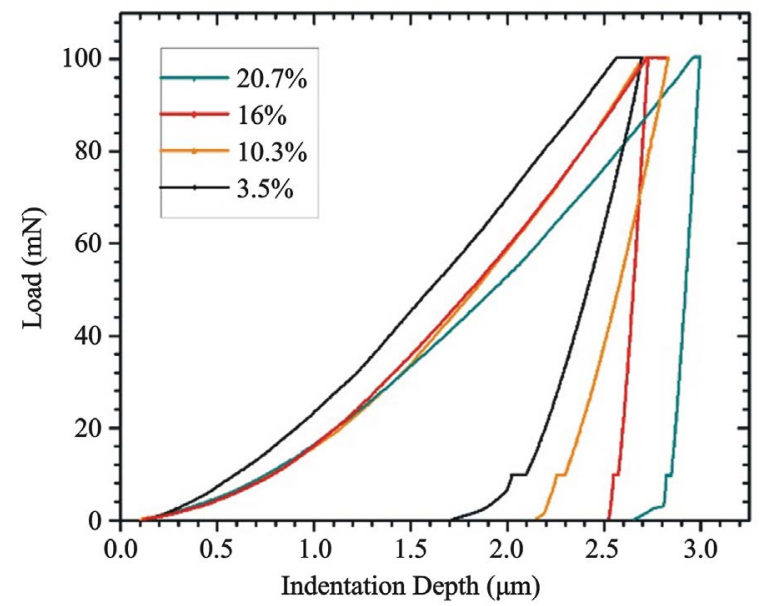

(b)

Figure 5. Load vs depth profile for (a) pure Al and (b) Al 6061 using $100 \mathrm{mN}$ load. 
pure $\mathrm{Al}$, indentation depth increased from $2.5 \mu \mathrm{m}$ to $3.5 \mu \mathrm{m}$ for the same constant load $100 \mathrm{mN}$ as the total amount of porosity increased from $1.9 \%$ to $15.1 \%$. And for Al 6061, this depth increase was from $2.4 \mu \mathrm{m}$ to 3.0 $\mu \mathrm{m}$ as surface porosity increased from $3.5 \%$ to $20.7 \%$. As outlined in the experimental section, there is an inverse relationship between contact depth $\left(h_{c}\right)$ and nanohardness and Young's modulus. Furthermore, the relationship between maximum indentation depth $\left(h_{\max }\right)$ and the contact depth $\left(h_{c}\right)$ is given by the following equation:

$$
h_{\max }=h_{c}+\frac{\pi-2}{\pi} h_{e}
$$

where $h_{e}$ is the elastic depth upon unloading. It can be concluded from this argument that, as the contact depth increases, contact area also increases and accordingly nanohardness and Young's modulus decrease. Fleck et al. [36] also studied the effect of porosity on indentation using both finite elemental analysis and cavity expansion model. These authors suggested that, resistance to indentation decreases with increasing porosity. Similar conclusion has been reached by others [37]-[39] regarding the relationship between nanohardness, Young's modulus and sample porosity.

\subsection{Scratch Behavior of Porous Pure Al and Al 6061}

Scratch testing was performed on highly porous pure $\mathrm{Al}$ and $\mathrm{Al} 6061$ having surface porosity $15.1 \%$ and $20.7 \%$ to observe the pores interaction during scratch. Scratch profile observations under the SEM provided much insight into the scratching behavior of the porous Al samples. Scratch width was measured from the SEM micrographs in order to compute the scratch hardness. It was observed that, scratch width was different for pure $\mathrm{Al}$ and Al 6061 specimens along the length of the scratch. The scratch hardness is calculated using simple Equation [40].

$H_{s}=8 W / \pi b^{2}$, where $W$ is the normal load, $b$ is the scratch width. This Equation can be converted into a convenient scratch hardness number (GPa) given as [41]:

$$
H_{s}=24.98 \mathrm{~m} / \mathrm{x}^{2}
$$

where $m$ is the normal load in grams and $x$ is the width in $\mu \mathrm{m}$. We can observe that the scratch width is a remarkable indicator for investigating the material resistance against the scratch deformation. As the scratch width of porous $\mathrm{Al} 6061$ specimen was larger than porous pure $\mathrm{Al}$ specimen, the scratch hardness was lower in $\mathrm{Al}$ 6061 (Table 7).

The normal hardness obtained from the nanoindentation test is the resistance of material against local deformation created by penetrating an indenter vertically, whereas scratch hardness is the response of material under dynamic deformation of the surface which is caused by the interfacial friction between the indenter and the material [42].

When the indenter slides on the work surface, forces produce horizontal compressive stress in front of the indenter but a corresponding tensile stress behind it [43]. The tensile stress would easily cause surface cracking. Moreover, with increase in the amount of porosity, the link up of pores and the distance cracks need to travel before meeting another pore is shorter. Thus, increasing fracturing of material.

Table 6. Nanoindentation test data.

\begin{tabular}{cccccc}
\hline $\begin{array}{c}\text { Pure Al surface porosity } \\
(\%)\end{array}$ & $\begin{array}{c}\text { Young's modulus } \\
\text { (GPa) }\end{array}$ & $\begin{array}{c}\text { Hardness } \\
(\mathbf{G P a})\end{array}$ & $\begin{array}{c}\text { Al 6061 surface porosity } \\
(\mathbf{\%})\end{array}$ & $\begin{array}{c}\text { Young's modulus } \\
\text { (GPa) }\end{array}$ & $\begin{array}{c}\text { Hardness } \\
(\mathbf{G P a})\end{array}$ \\
\hline $\mathbf{1 . 9}$ & 31.49 & 0.56 & 3.5 & 57.32 & 0.67 \\
$\mathbf{5 . 8}$ & 24.94 & 0.52 & 10.2 & 51.22 & 0.64 \\
$\mathbf{1 2 . 5}$ & 22.01 & 0.42 & 16.0 & 19.70 & 0.48 \\
$\mathbf{1 5 . 1}$ & 16.63 & 0.37 & 20.7 & 10.11 & 0.39 \\
\hline
\end{tabular}

Table 7. Scratch test data.

\begin{tabular}{cccc}
\hline \% Surface porosity & Scratch width $(\boldsymbol{\mu m})$ & Scratch length $(\mathbf{m m})$ & Scratch hardness $(\mathrm{GPa})$ \\
\hline Pure Al (15.1) & 210 & 5 & 0.05 \\
Al 6061 (20.7) & 240 & 5 & 0.04 \\
\hline
\end{tabular}


In case of pure $\mathrm{Al}$, periodic Hertzian cracksperpendicular to sliding direction (Figure 6) are observed.The insert in Figure 6 is a magnified image of the cracks. The deformation caused by the indenter contact in $\mathrm{Al} 6061$ specimen results in grain pull out from the scratch trackwhich ultimately leads to material loss (Figure 7(a)). Furthermore, pore edges represent stress concentration areas which tend to fracture with the passing of the indenter. This is evident from the cracks initiating from pore edge. Figure 7(b) shows the extension of these cracks due to the motion of the indenter.

As the load applied here is very small $(1 \mathrm{~N})$, the damage featuresare not extensive, but grain dislodgement and cracks formation in the specimens indicate that scratching is highly sensitive to the amount of porosity.

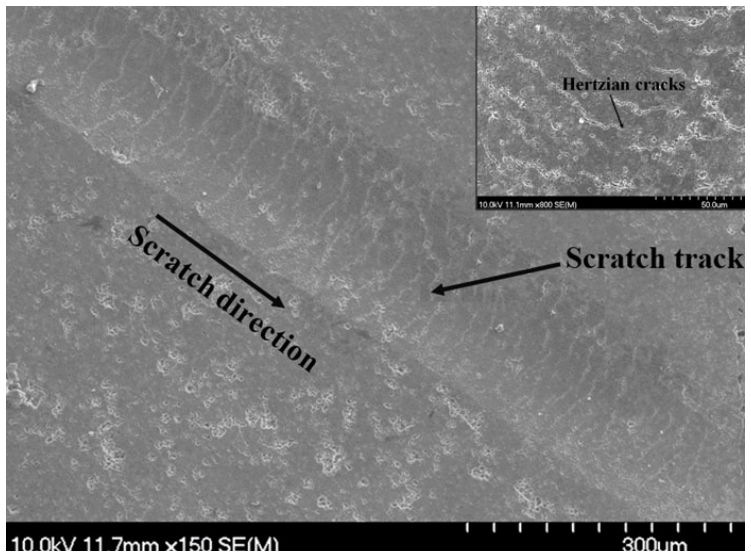

Figure 6. SEM images of porous pure $\mathrm{Al}$ scratch behavior.
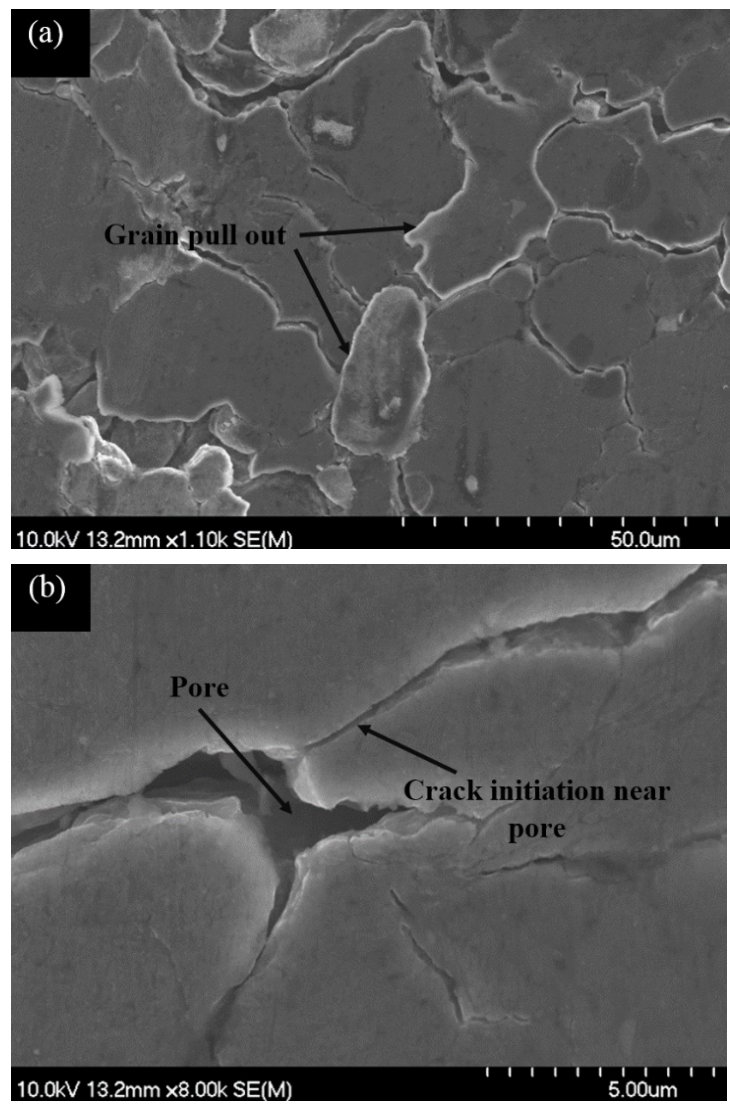

Figure 7. SEM images of porous Al 6061 scratch behavior. (a) Grain pull out from the scratch track; (b) Crack initiation from pore edge. 


\subsection{Effect of Surface Porosity on Wear and Friction}

Figure 8 represents the correlation between weight loss and sliding distance for pure Al (1.9\% porosity) and Al 6061 (3.5\% porosity). The plots reveal a somewhat linear increase in weight loss with sliding distance. As expected, it is observed that at any given sliding distance, weight loss increases with applied load as is evident by the upward shift in the weight loss versus sliding distance curve. This trend is in agreement with the other researchers [44]-[58]. To investigate the effect of porosity on wear, wear rate, calculated as the slopes of the weight loss versus sliding distance, is plotted as a function of \% surface porosity. The wear rate of pure Al containing $1.9 \%, 5.8 \%, 12.7 \%$ and $15.1 \%$ porosity and of $\mathrm{Al} 6061$ containing 3.5\%, 10.3\%, 16.0\% and 20.7\% porosity are plotted in Figure 9 and Figure 10 respectively. It can be seen from the Figures that the wear rate increases

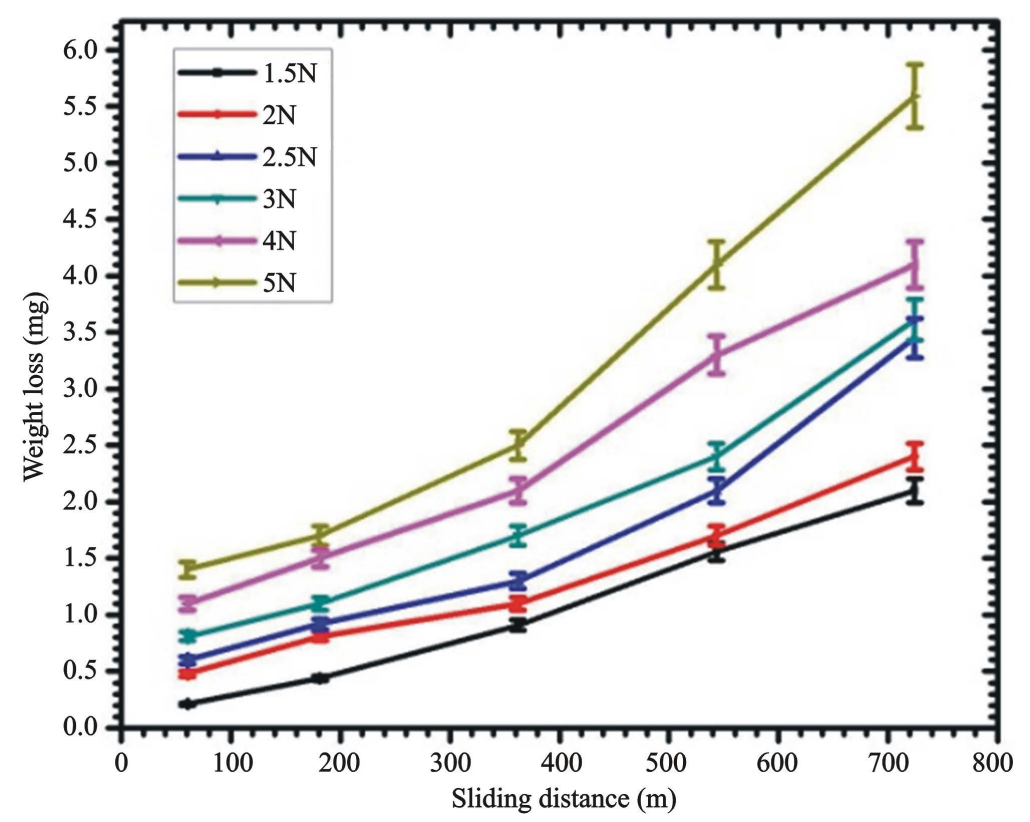

(a)

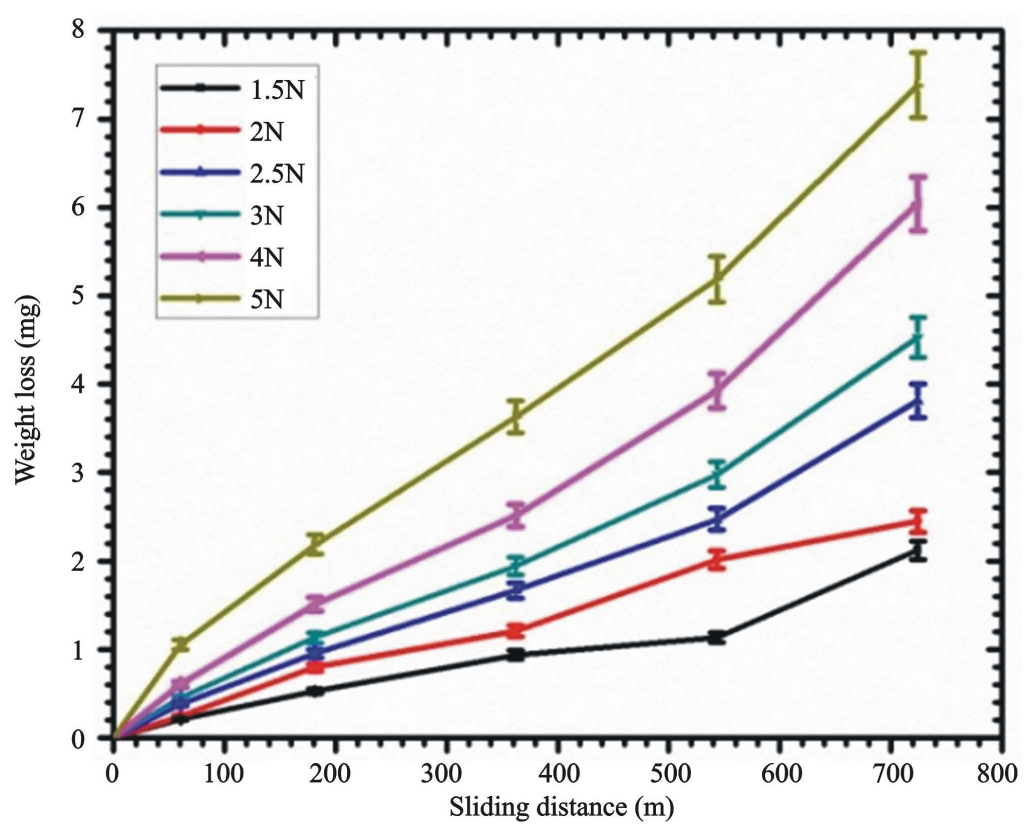

(b)

Figure 8. Weight loss versus sliding distance curve for (a) pure $\mathrm{Al}$ (1.9\% porosity) and (b) Al 6061(3.5\% porosity). 


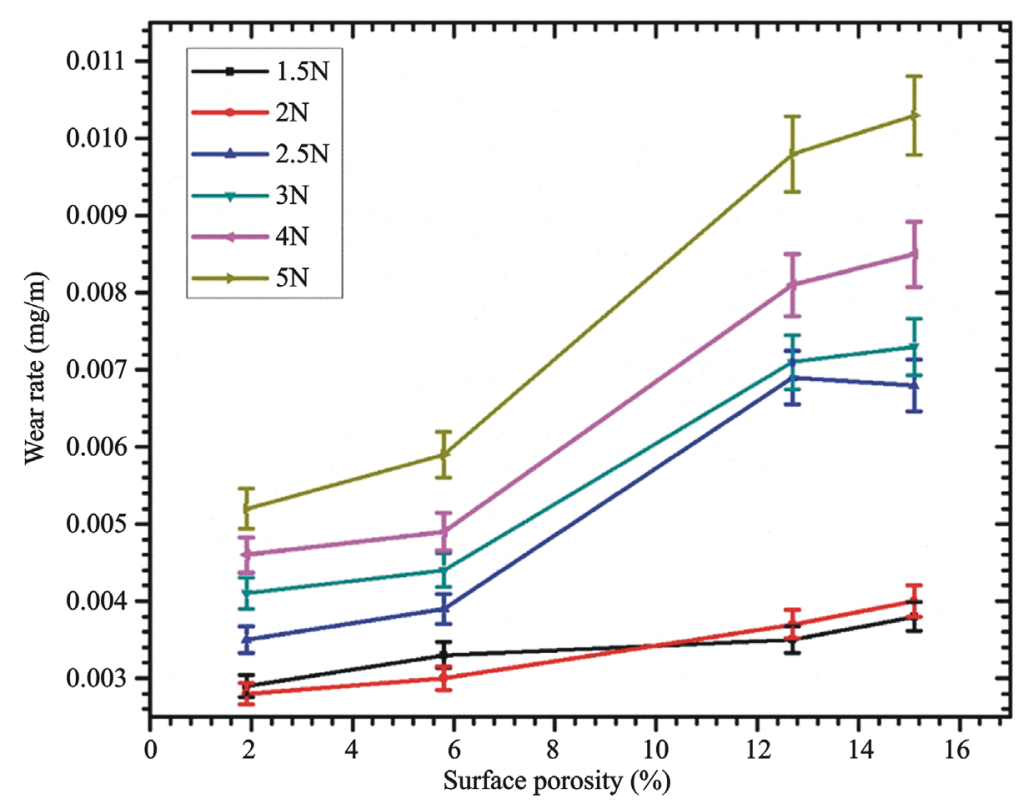

Figure 9. Wear rate versus surface porosity for pure $\mathrm{Al}$ under $10 \mathrm{~Hz}$ frequency.

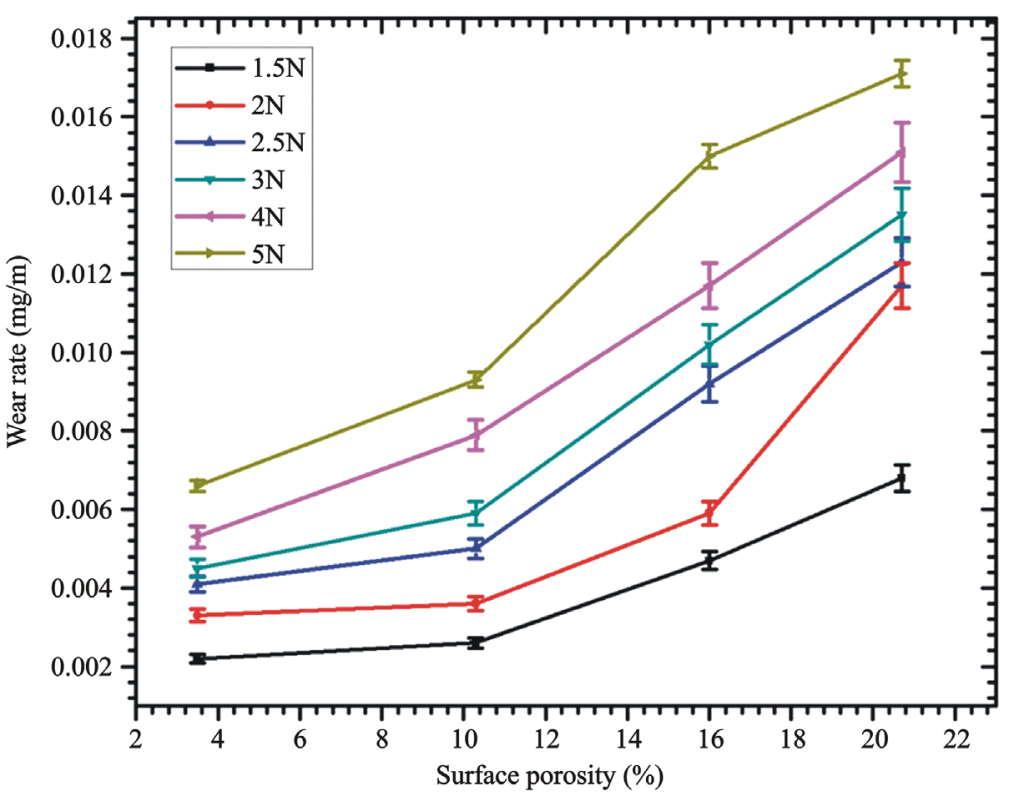

Figure 10. Wear rate versus surface porosity for Al 6061 under $10 \mathrm{~Hz}$ frequency.

with an increase in surface porosity in both cases. For pure $\mathrm{Al}$, wear rate doubles as surface porosity increases from $1.9 \%$ to $15.1 \%$ under $2.5 \mathrm{~N}$ load. Similar trend is also found under other loads. On the other hand, for $\mathrm{Al}$ 6061, wear rate increases two and half times when surface porosity increases from $7.5 \%$ to $20.7 \%$ under $2.5 \mathrm{~N}$ load. At high porosity, the surface roughness of the material increases, consequently the possibility of the generation of wear debris increases as a result of asperity-asperity contact. Furthermore, rise in porosity leads to drop in hardness of the material and therefore reduces the rate of wear.

The coefficient of friction is plotted as a function of porosity in Figure 11. As shown in the Figure, the coefficient of friction increases with increasing porosity. The coefficient of friction of the pure Al specimens containing $1.9 \%, 5.8 \%, 12.7 \%$ and $15.1 \%$ porosity were determined to be $0.41,0.44,0.57$, and 0.63 . And for $\mathrm{Al}$ 6061 , coefficient of friction of the specimens containing $3.5 \%, 10.3 \%, 16.0 \%$ and $20.7 \%$ were determined to be 


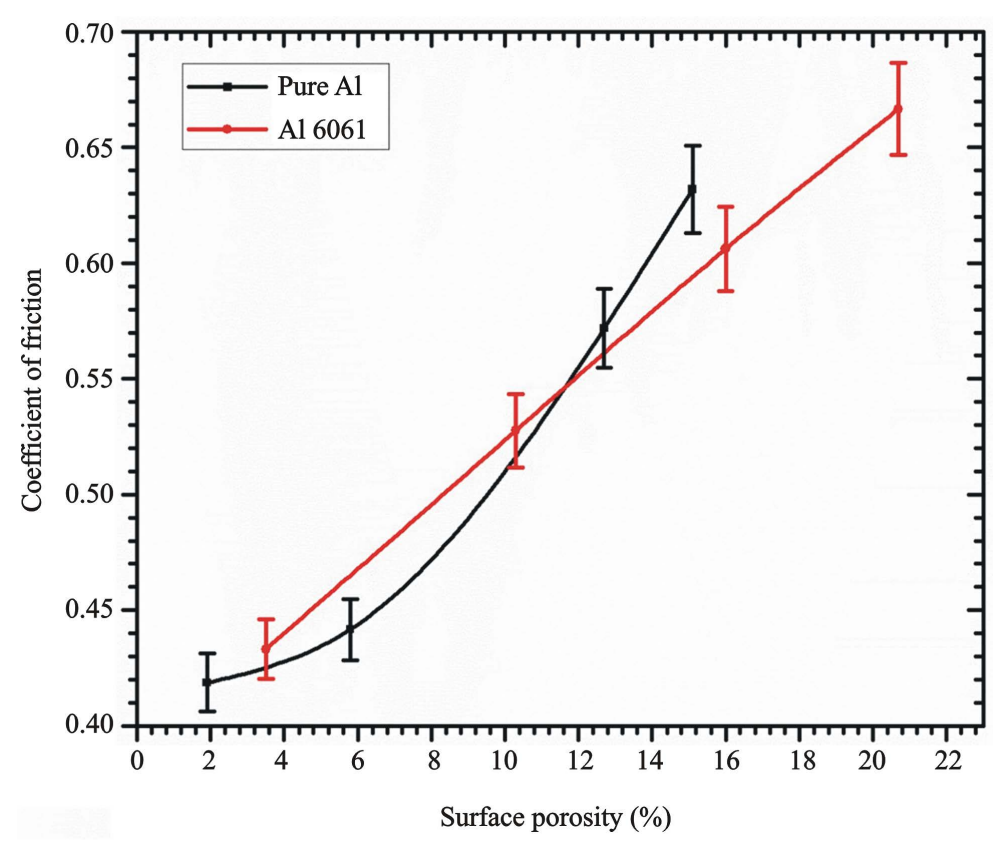

Figure 11. COF vs surface porosity for pure $\mathrm{Al}$ and $\mathrm{Al} 6061$ at $3 \mathrm{~N}$ load.

0.43, $0.52,0.60$ and 0.66 respectively. At high porosity, the surface roughness of the material increases; consequently the possibility of the generation of wear debris increases as a consequenceof asperity-asperity contact. Therefore, the rise in the coefficient of friction with increasing porosity might be attributed to the formation of more asperity-asperity contact during sliding.Yalcin [59] found similar results (increase in coefficient of friction with increasing porosity). He further suggested that, under dry friction conditions, a decrease in the coefficient of friction results in a decrease in the mass loss of the porous material.

\subsection{Worn Surface Evolution}

Worn surfaces of pure $\mathrm{Al}$ and $\mathrm{Al} 6061$ specimens were analyzed using scanning electron microscopy. Figure 12 and Figure 13 show worn surface morphologies of pure $\mathrm{Al}$ and $\mathrm{Al} 6061$ specimen containing 12.7\% and 16.0\% porosity respectively under $2.5 \mathrm{~N}$ load and $10 \mathrm{~Hz}$ frequency. Wear tracks are characterized by surface deformation and heavy damage in the form of longitudinal grooves extending parallel to the sliding direction which are clearly observed in Figure 12(a) and Figure 13(a) as evidence of abrasion. This process of material removal from the surface via plastic deformation during abrasion occurs by ploughing. During ploughing, ridges form along the sides of the ploughed grooves regardless of whether or not wear particles are formed. These ridges become flattened and eventually fracture after repeated loading and unloading cycles. Based on the experimental observations in this study, several factors can be identified that affect wear resistance of the sintered Al specimens, namely amount of porosity, pore size, shape, hardness and operating conditions (load and frequency). As pore represents stress concentration sites, crackstrend to form and propagatewith the reciprocating motion of the slider [60]. This is apparent from the cracks extending near the pores which are shown in Figure 12(b) and Figure 13(b).

EDS analysis was conducted on the worn surfaces of pure Aland Al 6061 alloy and is shown in Figure 14. EDS confirmed that, the worn surfaces contained a considerable amount of oxygen. The presence of oxygen on the worn surface is indicative of oxidative wear. As sliding takes place, the increase in temperature at the interface promotes the formation of oxides. Absence of Fe implies that, there is no material transfer from the counterface (AISI 52100 bearing steel ball). As a result, mechanical mixing of materials did not take place between the two sliding surface.

The size and shape of wear debris were analyzed using scanning electron microscopy which is shown in Figure 15. It is clearly seen that wear debris generated from pure Al are smaller in size than those generated from $\mathrm{Al} \mathrm{6061.} \mathrm{This} \mathrm{might} \mathrm{be} \mathrm{due} \mathrm{to} \mathrm{the} \mathrm{fact} \mathrm{that} \mathrm{pure} \mathrm{Al}$ exhibits smaller pore size and lower amount of surface porosity. The difference in wear debris size between pure $\mathrm{Al}$ and $\mathrm{Al} 6061$ explains why the grooves on the wear 

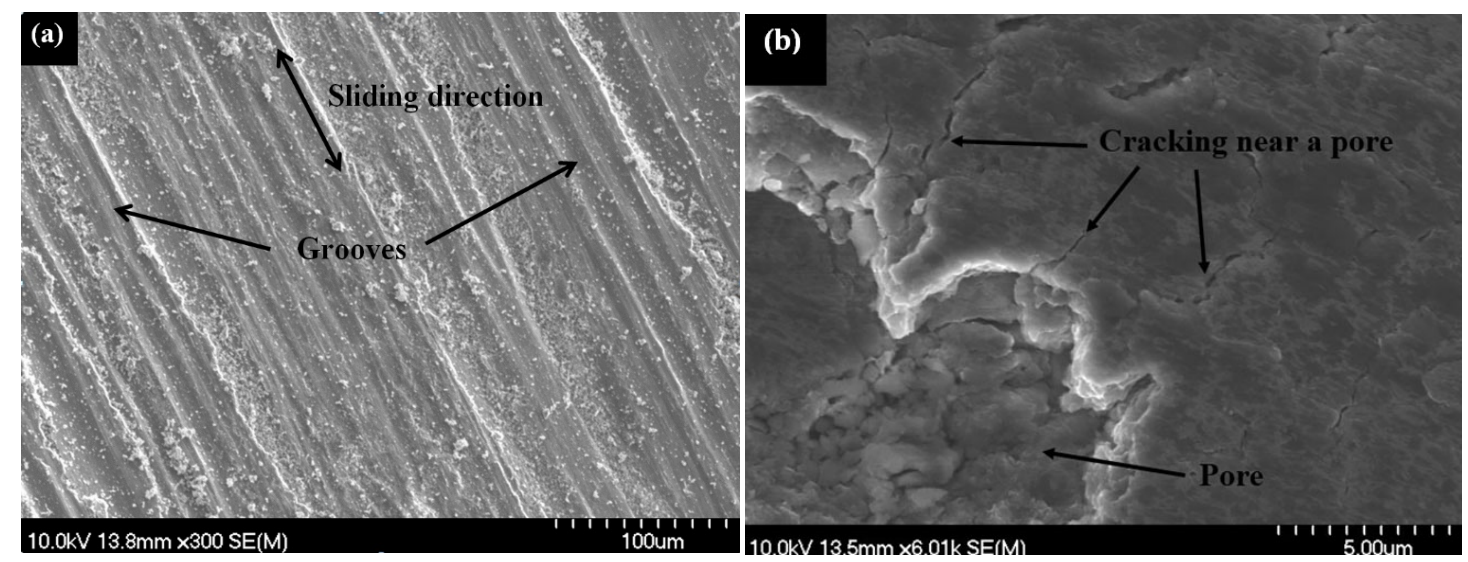

Figure 12. SEM micrograph of worn surface of pure $\mathrm{Al}(12.7 \%$ surface porosity) at $2.5 \mathrm{~N}$ load and $10 \mathrm{~Hz}$.
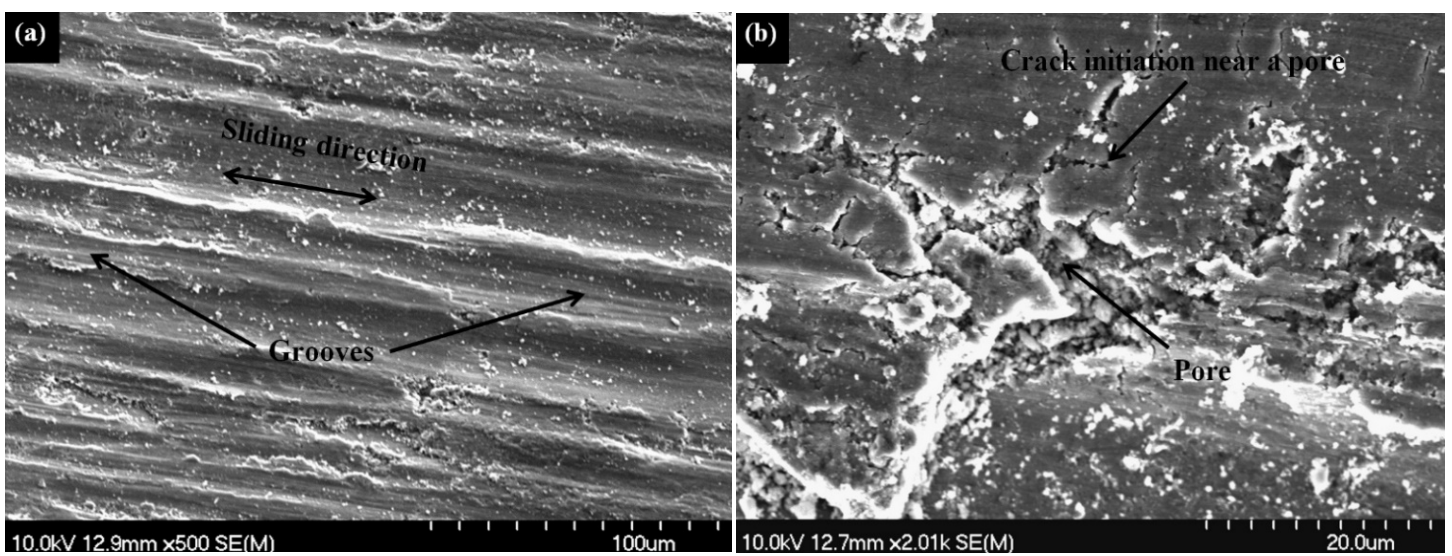

Figure 13. SEM micrograph of worn surface of $\mathrm{Al} 6061$ (16.01\% surface porosity) at $2.5 \mathrm{~N}$ load and $10 \mathrm{~Hz}$.
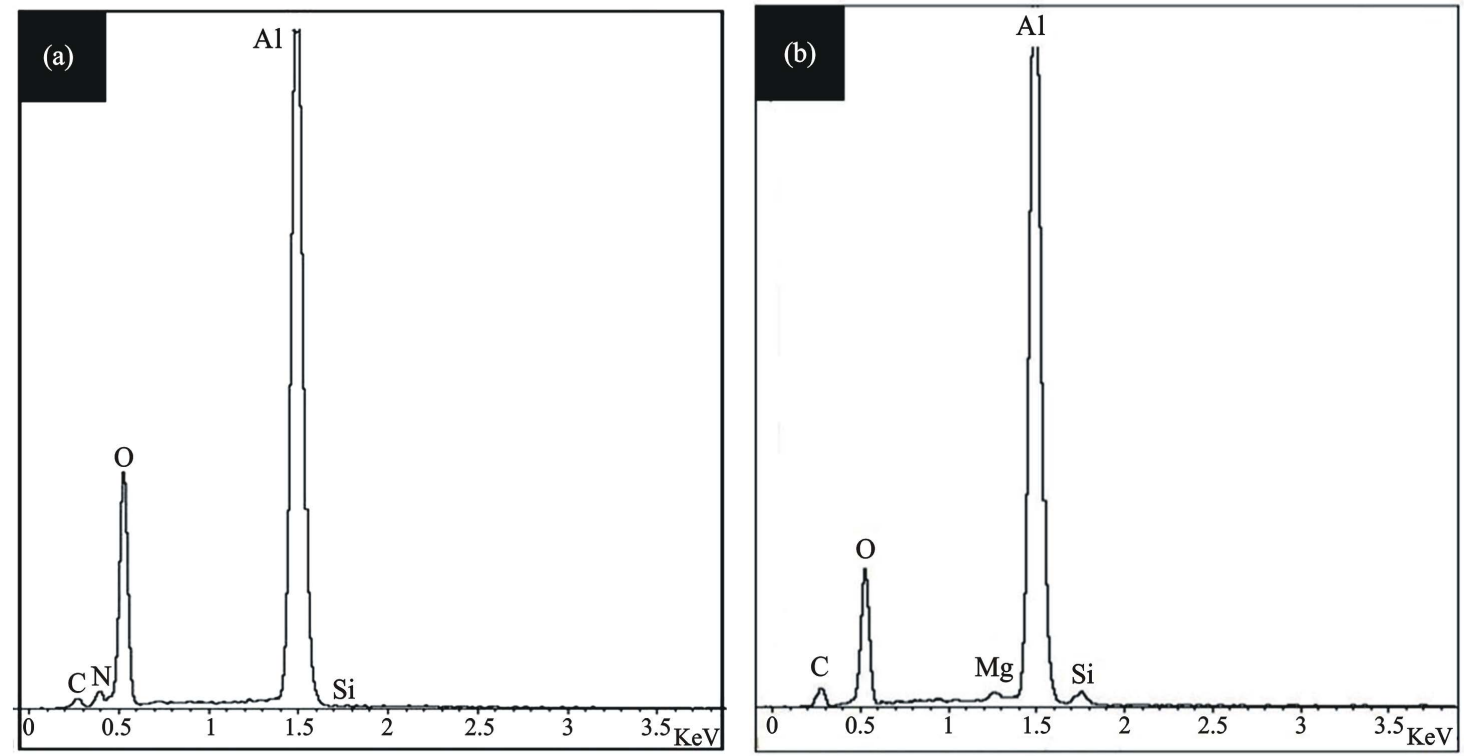

Figure 14. EDS analysis of worn surface. (a) Pure Al; (b) Al 6061. 

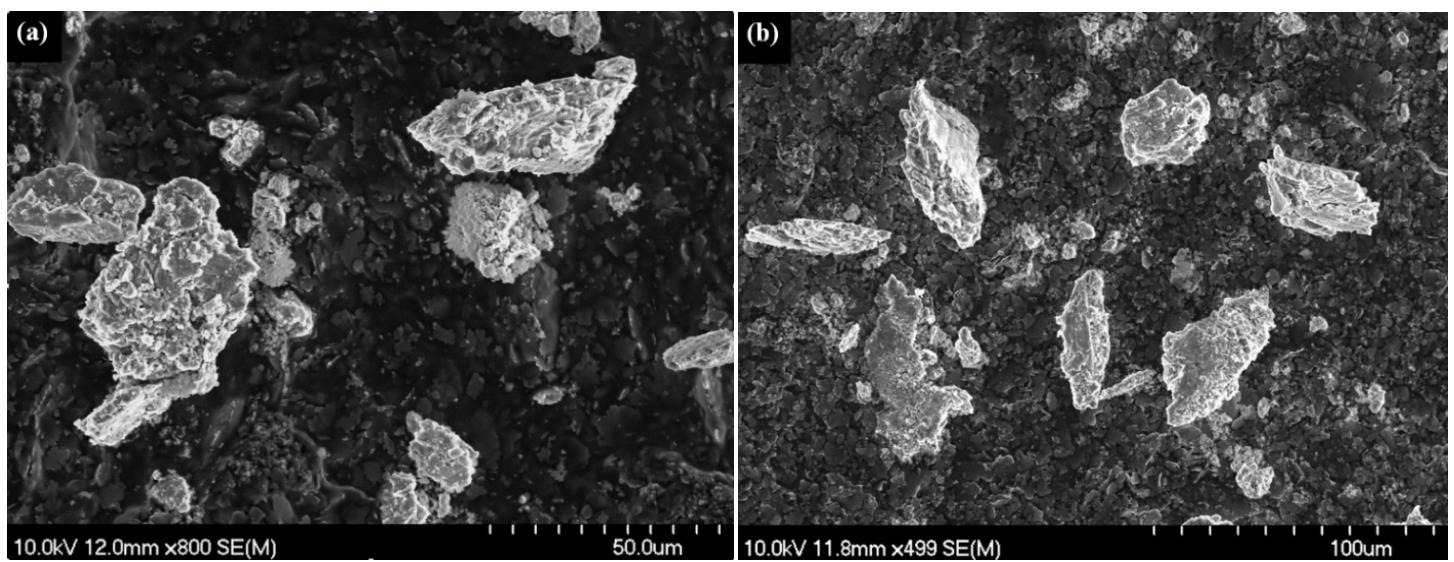

Figure 15. Wear debris at $2.5 \mathrm{~N}$ load and $10 \mathrm{~Hz}$. (a) Pure Al; (b) Al 6061.

track of pure Al are narrower than those of Al 6061 (Figure 12(a) and Figure 13(a)) as wear debris of different sizes slide on the surface of the Al specimens. Abrasive wear seems to be the dominating wear mechanism operating under the current conditions. That is, as porosity increases, surface roughness increases which gives rise to generation of large number of wear debris which in turn accelerates third body abrasion.

\section{Conclusions}

In the present work, the effect of surface porosity on tribological properties of pure $\mathrm{Al}$ and Al 6061 was studied. The following conclusions can be drawn:

1) There is an inverse relationship between the hardness and porosity content of Al alloys. For Pure Al, a reduction in hardness of about $40 \%$ is observed as surface porosity increases from $1.9 \%$ to $15.1 \%$ and for Al 6061 , $90 \%$ hardness reduction is observed as porosity increases from $3.5 \%$ to $20.7 \%$.

2) During scratch, large crack formation and Al grain dislodgement inside the track is observed for highly porous Al specimens. This behavior indicates scratch sensitivity to the amount and distribution of porosity.

3) Due to the combined effect of surface roughness and low hardness, high porosity is associated with low wear resistance for $\mathrm{Al}$ alloys.

4) The rise in the coefficient of friction with increasing porosity is attributed to the formation of more asperity-asperity contact during sliding.

5) A predominance of abrasive and oxidative wear mechanisms was identified on both pure $\mathrm{Al}$ and $\mathrm{Al} 6061$ alloy. Increase in porosity gives rise to large number of wear debris which in turn accelerates third body abrasion.

\section{Acknowledgements}

The authors acknowledge the financial support provided by Auto21 and Mr. Randy Cooke for his assistance in sample preparation.

\section{References}

[1] Yust, C.S. (1985) Tribology and Wear. International Metals Reviews, 30, 141-154.

[2] Saka, N., Eleiche, A.M. and Suh, N.P. (1977) Wear of Metals at High Sliding Speeds. Wear, 44, 109-125. http://dx.doi.org/10.1016/0043-1648(77)90089-8

[3] Prasad, B.K., Venkateswarlu, K., Modi, O.P., Jha, A.K., Das, S., Dasgupta, R. and Yegneswaran, A.H. (1998) Sliding Wear Behavior of Some Al-Si Alloys: Role of Shape and Size of Si Particles and Test Conditions. Metallurgical and Materials Transactions A, 29, 2747-2752. http://dx.doi.org/10.1007/s11661-998-0315-7

[4] Shivanath, R., Sengupta, P.K. and Eyre, T.S. (1977) Wear of Aluminum-Silicon Alloys. The British Foundrymen, 70, 349.

[5] Yassen, R.S. and Dwarakadasa, E.S. (1983) Wear of Aluminium under Dry Sliding Conditions. Wear, 84, 375-379. http://dx.doi.org/10.1016/0043-1648(83)90277-6 
[6] Bocchini, G.F. (1986) The Influence of Porosity on the Characteristics of Sintered Materials. International Journal of Powder Metallurgy, 22, 185-202.

[7] Proudhon, H., Savkova, J., Basseville, S., Guipont, V., Jeandin, M. and Cailletaud, G. (2014) Experimental and Numerical Wear Studies of Porous Reactive Plasma Sprayed Ti-6Al-4V/TiN Composite Coating. Wear, 311, 159-166. http://dx.doi.org/10.1016/j.wear.2014.01.012

[8] Zhang, L., Qu, X.-H., Duan, B-H., He, X.-B. and Qin, M.-L. (2008) Effect of Porosity on Wear Resistance of SiC $/ \mathrm{Cu}$ Composites Prepared by Pressureless Infiltration. Transactions of Nonferrous Metals Society of China, 18, 1076-1082. http://dx.doi.org/10.1016/S1003-6326(08)60184-3

[9] Chen, Q., Li, D. and Cook, B. (2009) Is Porosity Always Detrimental to the Wear Resistance of Materials? A Computational Study on the Effect of Porosity on Erosive Wear of TiC/Cu Composites. Wear, 267, 1153-1159. http://dx.doi.org/10.1016/j.wear.2008.12.058

[10] Simchi, A. and Danninger, H. (2004) Effects of Porosity on Delamination Wear Behaviour of Sintered Plain Iron. Powder Metallurgy, 47, 73-80. http://dx.doi.org/10.1179/003258904225015545

[11] Dubrujeaud, B., Vardavoulias, M. and Jeandin, M. (1994) The Role of Porosity in the Dry Sliding Wear of a Sintered Ferrous Alloy. Wear, 174, 155-161. http://dx.doi.org/10.1016/0043-1648(94)90097-3

[12] Li, D.Y. and Luo, Y.C. (2001) Effects of TiN Nano-Particles on Porosity and Wear Behavior of TiC/TiNi Tribo Composite. Journal of Materials Science Letters, 20, 2249-2252. http://dx.doi.org/10.1023/A:1017909723229

[13] Hamid, A.A., Ghosh, P., Jain, S. and Ray, S. (2006) Influence of Particle Content and Porosity on the Wear Behaviour of Cast in Situ $\mathrm{Al}(\mathrm{Mn})-\mathrm{Al}_{2} \mathrm{O}_{3}\left(\mathrm{MnO}_{2}\right)$ Composite. Wear, 260, 368-378. http://dx.doi.org/10.1016/j.wear.2005.02.120

[14] Sarikaya, O. (2005) Effect of Some Parameters on Microstructure and Hardness of Alumina Coatings Prepared by the Air Plasma Spraying Process. Surface \& Coatings Technology, 190, 388-393. http://dx.doi.org/10.1016/j.surfcoat.2004.02.007

[15] Raghukiran, N. and Kumar, R. (2013) Processing and Dry Sliding Wear Performance of Spray Deposited HyperEutectic Aluminum-Silicon Alloys. Journal of Materials Processing Technology, 213, 401-410. http://dx.doi.org/10.1016/j.jmatprotec.2012.10.007

[16] Kanchanomaia, C., Saengwichian, B. and Manonukul, A. (2013) Delamination Wear of Metal Injection Moulded 316L Stainless Steel. Wear, 267, 1665-1672. http://dx.doi.org/10.1016/j.wear.2009.06.019

[17] Tekmen, C., Ozdemir, I., Cocen, U. and Onel, K. (2003) The Mechanical Response of Al-Si-Mg/SiCp Composite: Influence of Porosity. Materials Science and Engineering A, 360, 365-371. http://dx.doi.org/10.1016/S0921-5093(03)00461-1

[18] Danninger, H., Jangg, G., Weiss, B. and Stickler, R. (1993) Microstructure and Mechanical Properties of Sintered Iron. Part I. Basic Considerations and Review of Literature. Powder Metallurgy International, 25, 111-117.

[19] Bergmark, A., Alzati, L. and Persson, U. (2002) Crack Initiation and Crack Propagation in Copper Powder Mixed PM Steel. Powder Metallurgy Progress, 2, 222-230.

[20] Gerard, D.A. and Koss, D.A. (1990) Low Cycle Fatigue Crack Initiation: Modeling the Effect of Porosity. International Journal of Powder Metallurgy, 26, 337-343.

[21] Sahin, Y. (2003) Preparation and Some Properties of SiC Particle Reinforced Aluminium Alloy Composites. Materials and Design, 24, 671-679. http://dx.doi.org/10.1016/S0261-3069(03)00156-0

[22] Sahin, Y. and Acilar, M. (2003) Production and Properties of SiCp-Reinforced Aluminium Alloy Composites. Composites Part A, 34, 709-718. http://dx.doi.org/10.1016/S1359-835X(03)00142-8

[23] Yih, P. and Chung, D.D.L. (1997) Titanium Diboride Copper-Matrix Composites. Journal of Materials Science, 32, 1703-1709. http://dx.doi.org/10.1023/A:1018515714687

[24] Ray, S., Fishman, S.G. and Dhingra, A.K. (1988) Porosity in Foundry Composites Prepared by Vortex Method. Proceedings of the Cast Reinforced Metal Composites, Chicago, 24-30 September 1988, 77-86.

[25] Mathew, B.A. and Mastromatteo, R. (2002) Metal Injection Moulding for Automotive Applications. Metal Powder Report, 57, 20-23. http://dx.doi.org/10.1016/S0026-0657(02)85078-0

[26] Bocchini, G.F. (1986) Influence of Porosity on the Characteristics of Sintered Materials. International Journal of Powder Metallurgy, 22, 185-188.

[27] Klar, E. and Samal, P.K. (1994) Powder Metallurgy Stainless Steels. In: Eisen, W.B. and German, R.M., Eds., ASM Handbook, Powder Metal Technologies and Applications, Volume 7, ASM International, Ohio, 474-482.

[28] Deshpande, P. and Lin, R. (2006) Wear Resistance of WC Particle Reinforced Copper Matrix Composites and the Effect of Porosity. Materials Science and Engineering A, 418, 137-145. http://dx.doi.org/10.1016/j.msea.2005.11.036

[29] Hardin, R.A. and Beckermann, C. (2007) Effect of Porosity on the Stiffness of Cast Steel. Metallurgical and Materials 
Transactions A, 12, 2992-3006. http://dx.doi.org/10.1007/s11661-007-9390-4

[30] Suh, N.P. (1977) An Overview of the Delamination Theory of Wear. Wear, 44, 1-16. http://dx.doi.org/10.1016/0043-1648(77)90081-3

[31] Vardavoulias, M., Jouanny-Tresy, C. and Jeandin, M. (1993) Sliding-Wear Behaviour of Ceramic Particle-Reinforced High-Speed Steel Obtained by Powder Metallurgy. Wear, 165, 141-149. http://dx.doi.org/10.1016/0043-1648(93)90329-K

[32] Gui, M., Kang, S.B. and Lee, J.M. (2000) Influence of Porosity on Dry Sliding Wear Behaviour in Spray Deposited Al-6Cu-Mn/SiCp Composite. Materials Science and Engineering A, 293, 146-156. http://dx.doi.org/10.1016/S0921-5093(00)01052-2

[33] Bertilsson, I., Karlsson, B. and Wasen, J. (1994) Fatigue Properties of Sintered Steels. Proceedings of the International Conference on Powder Metallurgy and Particulate Materials, Toronto, 8-11 May 1994, 19-32.

[34] Islam, M.A. and Farhat, Z.N. (2011) Effect of Porosity on Dry Sliding Wear of Al-Si Alloys. Tribology International, 44, 498-504. http://dx.doi.org/10.1016/j.triboint.2010.12.007

[35] Oliver, W.C. and Pharr, G.M. (1992) Improved Technique for Determining Hardness and Elastic Modulus Using Load and Displacement Sensing Indentation Experiments. Journal of Materials Research, 7, 1564-1583. http://dx.doi.org/10.1557/JMR.1992.1564

[36] Fleck, N.A., Otoyo, H. and Needleman, A. (1992) Indentation on Porous Solids. International Journal of Solids and Structures, 29, 1613-1636. http://dx.doi.org/10.1016/0020-7683(92)90012-I

[37] Jang, B.K. and Matsubara, H. (2005) Influence of Porosity on Hardness and Young's Modulus of Nanoporous EB-PVD TBCs by Nanoindentation. Materials Letters, 59, 3462-3466. http://dx.doi.org/10.1016/j.matlet.2005.06.014

[38] Chen, X., Xiang, Y. and Vlassak, J.J. (2006) Novel Technique for Measuring the Mechanical Properties of Porous Materials by Nanoindentation. Journal of Materials Research, 21, 715-724. http://dx.doi.org/10.1557/jmr.2006.0088

[39] Ling, Z., Wang, X. and Ma, J. (2008) The Response of Porous $\mathrm{Al}_{2} \mathrm{O}_{3}$ Probed to Nanoindentation. Materials Science and Engineering A, 483-484, 285-288. http://dx.doi.org/10.1016/j.msea.2006.10.195

[40] Sinha, S.K., Reddy, S.U. and Gupta, M. (2006) Scratch Hardness and Mechanical Property Correlation for Mg/SiC and $\mathrm{Mg} / \mathrm{SiC} / \mathrm{Ti}$ Metal-Matrix Composites. Tribology International, 39, 184-189. http://dx.doi.org/10.1016/j.triboint.2005.04.017

[41] ASTM G171-03(2009) e2, Standard Test Method for Scratch Hardness of Materials Using a Diamond Stylus. ASTM Standard Designation.

[42] Yan, C. and Zhang, L. (1995) Single-Point Scratching of 6061 Al Alloy Reinforced by Different Ceramics Particles. Applied Composite Materials, 1, 431-447. http://dx.doi.org/10.1007/BF00706503

[43] Farokhzadeh, K., Edrisy, A., Pigott, G. and Lidster, P. (2013) Scratch Resistance Analysis of Plasma-Nitrided Ti-6Al4V Alloy. Wear, 302, 845-853. http://dx.doi.org/10.1016/j.wear.2013.01.070

[44] Gyimah, G.K., Chen, D. and Huang, P. (2013) Dry Sliding Studies of Porosity on Sintered Cu-Based Brake Materials. Transaction on Control and Mechanical Systems, 2, 219-224.

[45] Dwivedi, D.K. (2010) Adhesive Wear Behaviour of Cast Aluminium-Silicon Alloys: Overview. Materials and Design, 31, 2517-2531. http://dx.doi.org/10.1016/j.matdes.2009.11.038

[46] Elmadagli, M., Perry, T. and Alpas, A.T. (2007) A Parametric Study of the Relationship between Microstructure and Wear Resistance of Al-Si Alloys. Wear, 262, 79-92. http://dx.doi.org/10.1016/j.wear.2006.03.043

[47] Chowdhury, M.A., Khalil, M.K., Nuruzzaman, D.M. and Rahaman, M.L. (2011) The Effect of Sliding Speed and Normal Load on Friction and Wear Property of Aluminum. International Journal of Mechanical \& Mechatronics Engineering IJMME-IJENS, 11, 53-57.

[48] Wei, M.X., Chen, K.M., Wang, S.Q. and Cui, X.H. (2011) Analysis for Wear Behaviors of Oxidative Wear. Tribology Letters, 42, 1-7. http://dx.doi.org/10.1007/s11249-010-9741-y

[49] Al-Samarai, R.A., Haftirman, Ahmad, K.R. and Al-Douri, Y. (2012) Effect of Load and Sliding Speed on Wear and Friction of Aluminum-Silicon Casting Alloy. International Journal of Scientific and Research Publications, 2, 3-6.

[50] Kumar, S. and Balasubramanian, V. (2010) Effect of Reinforcement Size and Volume Fraction on the Abrasive Wear Behaviour of AA7075 Al/SiCp P/M Composites-A Statistical Analysis. Tribology International, 43, 414-422. http://dx.doi.org/10.1016/j.triboint.2009.07.003

[51] Corrochanoa, J., Walker, J.C., Lieblich, M., Ibanez, J. and Rainforth, W.M. (2011) Dry Sliding Wear Behaviour of Powder Metallurgy Al-Mg-Si Alloy-MoSi ${ }_{2}$ Composites and the Relationship with the Microstructure. Wear, 270, 658665. http://dx.doi.org/10.1016/j.wear.2011.01.029

[52] Bermudez, M.D., Martinez-Nicolas, G., Carrion, F.J., Martinez-Mateo, I., Rodriguez, J.A. and Herrera, E.J. (2001) Dry 
and Lubricated Wear Resistance of Mechanically-Alloyed Aluminium-Base Sintered Composites. Wear, 248, 178-186. http://dx.doi.org/10.1016/S0043-1648(00)00553-6

[53] Yasmin, T., Khalid, A.A. and Haque, M.M. (2004) Tribological (Wear) Properties of Aluminum-Silicon Eutectic Base Alloy under Dry Sliding Condition. Journal of Materials Processing Technology, 153-154, 833-838. http://dx.doi.org/10.1016/j.jmatprotec.2004.04.147

[54] Hamn, M., Talib, I.A. and Daud, A.R. (1996) Effect of Element Additions on Wear Property of Eutectic Aluminium-Silicon Alloys. Wear, 194, 54-59. http://dx.doi.org/10.1016/0043-1648(95)06707-8

[55] Casellas, D., Beltran, A., Prado, J.M., Larson, A. and Romero, A. (2004) Microstructural Effects on the Dry Wear Resistance of Powder Metallurgy Al-Si Alloys. Wear, 257, 730-739. http://dx.doi.org/10.1016/j.wear.2004.03.011

[56] Sharifi, E.M. and Karimzadeh, F. (2011) Wear Behavior of Aluminum Matrix Hybrid Nanocomposites Fabricated by Powder Metallurgy. Wear, 271, 1072-1079. http://dx.doi.org/10.1016/j.wear.2011.05.015

[57] Rahimian, M., Parvin, N. and Ehsani, N. (2011) The Effect of Production Parameters on Microstructure and Wear Resistance of Powder Metallurgy Al- $\mathrm{Al}_{2} \mathrm{O}_{3}$ Composite. Materials and Design, 32, 1031-1038. http://dx.doi.org/10.1016/j.matdes.2010.07.016

[58] Ravindran, P., Manisekar, K., Rathika, P. and Narayanasamy, P. (2013) Tribological Properties of Powder MetallurgyProcessed Aluminium Self Lubricating Hybrid Composites with SiC Additions. Materials and Design, 45, 561-570. http://dx.doi.org/10.1016/j.matdes.2012.09.015

[59] Yalcin, B. (2009) Effect of Porosity on the Mechanical Properties and Wear Performance of 2\% Copper Reinforced Sintered Steel Used in Shock Absorber Piston Production. Journal of Material Science and Technology, 25, 577-582.

[60] Islam, M.A. and Farhat, Z.N. (2011) The Influence of Porosity and Hot Isostatic Pressing Treatment on Wear Characteristics of Cast and P/M Aluminum Alloys. Wear, 271, 1594-1601. http://dx.doi.org/10.1016/j.wear.2011.01.037 